\title{
A Model of Smolt-to-adult Survival in Terms of Salmon Growth through the Size Distribution of Predators
}

\author{
James J. Anderson \\ School of Aquatic and Fishery Science, University of Washington, Box 355020 Seattle, WA 98195-5020, USA
}

Keywords: growth, size, size-selection, survival, prey, salmon, gape-limited predators, apex predators

As a general rule, survival of juvenile salmon to adult spawners is thought to be determined by growth during the first year in the marine environment through size-selective removal of the smaller fish by predation and overwinter starvation (Beamish and Mahnken 2001). Numerous studies support this hypothesis (e.g., Beamish et al. 2004; Moss et al. 2005). However, other populations do not fit the "bigger is better" rule (Claiborne et al. 2014; Miller et al. 2013), nor does the estimated magnitude of size selection mortality account for the observed mortality (Beacham et al. 2018). Additionally, studies indicate significant ocean mortality on adult salmon (Seitz et al. 2019). However, studies on individually tagged salmon clearly indicate that large smolts have higher adult survival (Passolt and Anderson 2013). This paper explores a possible basis for the conflicting studies through a model that describes mortality of fish growing through a range of predator gape sizes.

The model is based on the assumption that predators only eat prey smaller than their gape size, so predation decreases as prey grow (Anderson 2019). The resulting smolt-to-adult ratio (SAR), characterizing ocean survival as a function of ocean entry size class $i$, is

$$
S A R_{i}=\exp \left(-H+\frac{s}{A \Phi(m / s)} \cdot \frac{x_{i} \Phi\left(-x_{i}\right)-\varphi\left(x_{i}\right)}{f\left(x_{i}, \bar{x}, m / s, C\right)}\right)
$$

where $x$ is the fish size normalized to the predator gape distribution as $x_{i}=\left(l_{i}-m\right) / s$ with $l_{i}$ the ocean entrance length of fish in size class $i, m$ is the mean predator gape size and $s$ is its standard deviation. The model assumes the distribution of gape-limited predator sizes can be represented as a normal distribution such that the normalized prey distribution can be represented by standard normal cumulative and density functions, $\Phi$ and $\varphi$. The ratio of the growth rate to the predator encounter rate is $A=\bar{g} \lambda$ where $\bar{g}$ is the mean cohort growth rate and $\lambda$ is the predator encounter rate. The contribution of apex predators is $H=\mu_{H} \cdot t_{H}$ where $\mu_{H}$ is the mortality rate and $t_{H}$ is the exposure duration. The growth rate of size-class $i$ relative to the mean cohort growth rate is described by the empirical function

$$
f\left(x_{i}, \bar{x}, m / s, C\right)=\frac{g_{i}}{\bar{g}}=2\left(1-1 /\left(1+\exp \left(C\left(1-\frac{x_{i}+m / s}{\bar{x}+m / s}\right)\right)\right)\right)
$$

Figure 1 illustrates the relative growth rate as a function of ocean entrance size $l_{i}$ for different values of the growth compensation parameter $C$ which accounts for increased growth rate of small members of a cohort after ocean entrance (Ali et al. 2003).

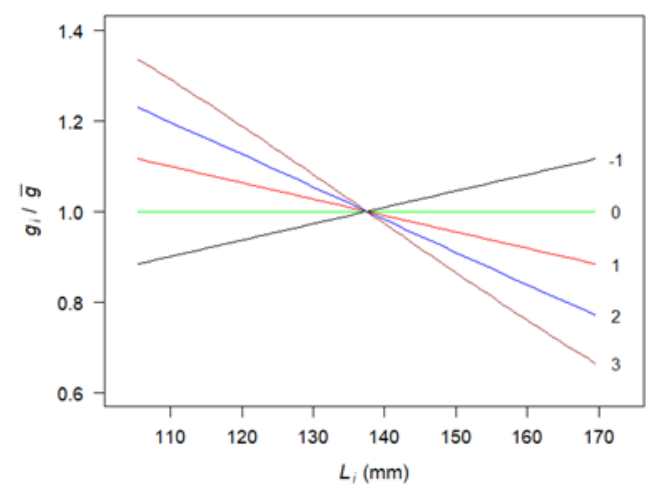

Fig. 1. Effect of ocean entrance fish length on relative growth rate from eqn (2) for values of $\mathrm{C}-1$ to 3.

To estimate the effects of the parameters on SAR, the model was fit to profiles of SAR vs. initial fish length. Convergence of a nonlinear weighted least-squares algorithm (nls) (R Core Team 2016) requires initial values of the 
predator distribution parameters $m$ and $s$. Thus, the data was fit using $1 \mathrm{~mm}$ incremented points on a $m \times s$ grid to yield best fit values of $A, C, H$ and residual square error (RSE) for each point.

To explore the processes controlling ocean survival the model was fit to SAR vs. length data of hatchery reared Snake River yearling Chinook salmon (Oncorhynchus tshawytscha). The juveniles were collected at Lower Granite Dam, measured for length and tagged with passive integrated transponder tags. The SAR was estimated for fish binned in successive $4 \mathrm{~mm}$ increments of tagging length. Data is available at the DART database (http://www.cbr.washington.edu/dart). Data for 2008 consisted of smolts that, after tagging, were placed in transport barges and released below Bonneville Dam, the last dam on the Snake-Columbia River hydrosystem. Data for 2009 consisted of fish that were released back into the river after tagging.

The range of the $m \times s$ grid was determined from stomach contents of the major salmon predators: Pacific hake (Merluccius productus) and jack mackerel (Trachurus symmetricus) captured salmon ranging between 50-250 $\mathrm{mm}$ in length (Emmett 2006), Aucklets (Aethia cristatella) captured salmon approximately $120 \mathrm{~mm}$ in length (Tucker et al. 2016) and apex predators, such as salmon sharks, have been observed to capture adult salmon between $57-100 \mathrm{~cm}$ in length (Seitz et al. 2019). From these observations the grid range of mean gape size was set at $m=$ $50-250 \mathrm{~mm}$ and the standard deviation of gape size was set at $s=4-204 \mathrm{~mm}$. The apex predators are generally classified as gape-unlimited predators and their effects are mostly captured by $H$.

2008
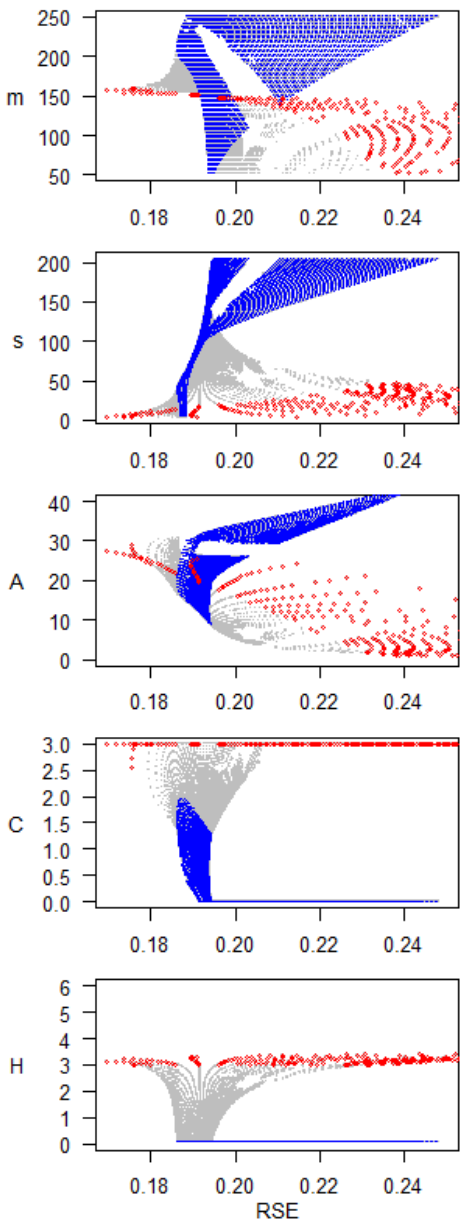

2009
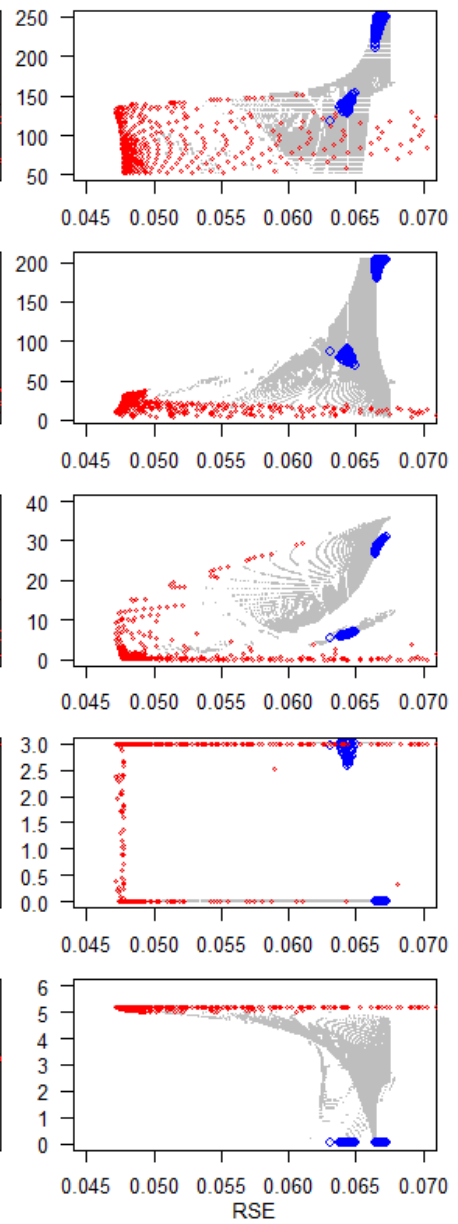

Fig. 2. Fitted model parameters for $m \mathrm{x} s$ grid points vs. RSE for smolt migration years 2008 and 2009. Region I parameter sets (red) encompass the upper boundary of $H$ and Region II points (blue) encompass the lower boundary.

Figure 2 illustrates the parameter space depicted by individual plots of $(m, s, A, C, H)$ against the corresponding RSE of each regression. Critical parameter regions correspond to the upper and lower ranges of apex predation $H$ depicted by red and blue points in the figures. Region I (red points) corresponds to parameters with 
high apex predator mortality and Region II (blue points) corresponds to parameters with low apex predator mortality.

Table 1. Best fit parameters for Snake River spring Chinook salmon migration year 2008 and 2009 for Region I and II of the parameter spaces. $S_{\text {apex }}$ and $S_{\text {gape }}$ are survivals resulting from apex and gape-limited predators respectively. The ratio of growth to predation, $\mathrm{g} / \bar{\mu}$ is based on $l_{0}=134 \mathrm{~mm}$ (see text).

\begin{tabular}{ccccccccccc}
\hline Region & Year & $m$ & $s$ & $A$ & $C$ & $H$ & $\overline{\mathrm{g}} / \bar{\mu}$ & $S_{\text {apex }}$ & $S_{\text {gape }}$ & RSE \\
& & $\mathrm{mm}$ & $\mathrm{mm}$ & $\mathrm{mm}$ & $\sim$ & $\sim$ & $\mathrm{mm}$ & $\sim$ & $\sim$ & $\sim$ \\
\hline I & 2008 & 156 & 4 & 27.3 & 3 & 3.2 & 27.3 & 0.421 & 0.491 & 0.169 \\
I & 2009 & 131 & 9 & 6.8 & 3 & 5.2 & 25.5 & 0.005 & 0.806 & 0.047 \\
II & 2008 & 149 & 89 & 11.6 & 1.5 & 0.1 & 20.1 & 0.95 & 0.033 & 0.192 \\
II & 2009 & 141 & 75 & 6.1 & 3 & 0.1 & 11.2 & 0.95 & 0.004 & 0.064 \\
\hline
\end{tabular}

Table 1 gives the parameters corresponding to the minimum RSE for each region. The mean size of the gapelimited predators is similar for both years and regions. However, the size standard deviation for Region I is a factor of 10 smaller than for Region II. Correspondingly, the contributions of apex predators are different for the two regions. In Region I, apex predators control SAR while in Region II, gape-limited predators control SAR. Also note Region I parameters have lower RSE, indicating better fits with the assumption of high apex predation.

To evaluate the model, $A$ and $C$ can be estimated independently. $A$ can be related to the ratio of growth to mortality rates as $\bar{g} / \bar{\mu}=A \Phi(\mathrm{m} / \mathrm{s}) / \Phi\left(-\bar{x}_{o}\right)$. For the independent estimate of the ratio, $\bar{g}$ was estimated between 0.5 to $1 \mathrm{~mm} \cdot \mathrm{d}^{-1}$ using otolith ring widths of Snake River spring Chinook captured off the Washington coast (Miller et al. 2014) and $\bar{\mu}$ was estimated as $\sim 0.08 \mathrm{~d}^{-1}$ from a regression of survival of acoustically tagged juvenile spring Chinook salmon transiting through the Columbia River plume (Brosnan et al. 2014). Thus, $g / \bar{\mu} \approx 11$ is within a factor of two of the model estimates. The compensation parameter $C$ was limited to values between 0 and 3 , which corresponds to the observed 10-50\% increase in growth after release from diet restriction observed by (Ali et al. 2003). The $H$ parameter can be in part evaluated by computing the corresponding predation exposure from $t_{H}=$ $H / \mu_{H}$. Using $H$ (Table 1) and $\mu_{H} \sim 0.008 \mathrm{~d}^{-1}$, from survival of Gulf of Alaska adult spring Chinook tagged with popup satellite archival tags (Seitz et al. 2019), $t_{H}$ falls between one and two years, which is within the typical ocean residence of spring Chinook.
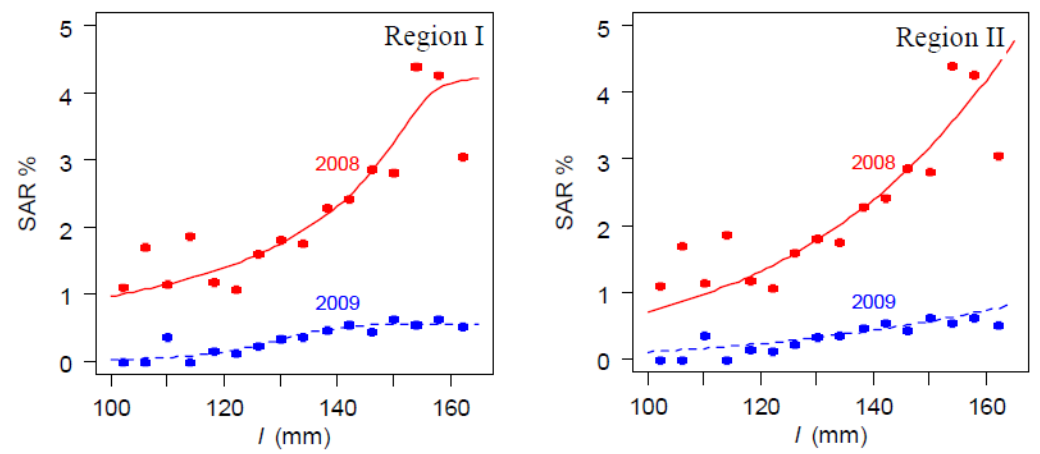

Fig. 3. Chinook salmon SAR vs. juvenile fish length binned in $4 \mathrm{~mm}$ intervals with lines produced by eqn (1) using parameters from Table 1 for Region I and II parameters.

Figure 3 illustrates the fit of SAR vs $l$ for the two regions. The Region I parameters capture a distinct step-like pattern for both 2008 and 2009 while Region II parameters do not. Importantly, the step feature, produced with Region I parameters, results because the mean fish entrance length $(\sim 133 \mathrm{~mm})$ and mean predator gape $(\sim 143 \mathrm{~mm})$ are similar while the standard deviation is small $(\sim 6 \mathrm{~mm})$. This allows fish with ocean entrance size greater than the predator gape mean to quickly escape predation such that their SAR changes little with size. Alternatively, with Region II predators, fish of all entrance sizes experience gape-limited predators and SAR increases with size.

The model reveals that processes controlling marine survival of the spring Chinook salmon can be explained by alternative predator-prey dynamics. For Region I parameters, the gape-limited predators that exhibit a narrow 
gape-frequency distribution requires a significant level of apex predation. For Region II parameters, the wider predator size distribution allows the SAR to be explained with little apex predation. With Region I ecology, fish recruitment is largely insensitive to ocean growth while with Region II ecology recruitment depends on growth over the first year or more of ocean residence. Importantly, a distinct step in the SAR vs. length profile only occurs when apex predators dominate. As an aside, the model demonstrated that changes in growth ring spacing with age is not a sensitive indicator of the effects of size-selective predation on stock recruitment.

In summary, the model introduces the effects of the predator size distribution on the survival of growing prey and suggests that fish recruitment is not wholly controlled by processes occurring during early ocean residence; apex predators can also have significant impacts. Finally, a central take-away of the analysis is that the predator size distribution is an important dimension that needs to be considered when studying fish recruitment.

\section{REFERENCES}

Ali, M., A. Nicieza, and R.J. Wootton. 2003. Compensatory growth in fishes: a response to growth depression. Fish and Fish. 4(2): 147-190. doi:10.1046/j.1467-2979.2003.00120.x.

Anderson, J.J. 2019. Survival of prey growing through gape-limited and apex predators. bioRxiv: 686964 . doi:10.1101/686964.

Beacham, T.D., H.A. Araujo, S. Tucker, and M. Trudel. 2018. Validity of inferring size-selective mortality and a critical size limit in Pacific salmon from scale circulus spacing. PLoS One. 13(6): e0199418. doi:10.1371/journal.pone.0199418.

Beamish, R.J., and C. Mahnken. 2001. A critical size and period hypothesis to explain natural regulation of salmon abundance and the linkage to climate and climate change. Prog. Oceanogr. 49(1): 423-437. doi:10.1016/S0079-6611(01)00034-9.

Beamish, R.J., C. Mahnken, and C.M. Neville. 2004. Evidence That Reduced Early Marine Growth is Associated with Lower Marine Survival of Coho Salmon. Trans. Am. Fish. Soc. 133(1): 26-33. doi:10.1577/T03-028.

Brosnan, I., D. Welch, E. Rechisky, and A. Porter. 2014. Evaluating the influence of environmental factors on yearling Chinook salmon survival in the Columbia River plume (USA). Mar. Ecol. Prog. Ser. 496: 181-196. doi:10.3354/meps 10550 .

Claiborne, A., J. Miller, L. Weitkamp, D. Teel, and R. Emmett. 2014. Evidence for selective mortality in marine environments: the role of fish migration size, timing, and production type. Mar. Ecol. Prog. Ser. 515: 187202. doi: $10.3354 / \mathrm{meps} 10963$.

Emmett, R.L. 2006. The relationships between fluctuations in oceanographic conditions, forage fishes, predatory fishes, predator food habits, and juvenile salmonid marine survival off the Columbia River. Ph.D. thesis, Oregon State Univ. Corvallis OR. 335 pp.

Miller, J.A., D.J. Teel, A. Baptista, and C.A. Morgan. 2013. Disentangling bottom-up and top-down effects on survival during early ocean residence in a population of Chinook salmon (Oncorhynchus tshawytscha). Can. J. Fish. Aquat. Sci. 70(4): 617-629. doi:10.1139/cjfas-2012-0354.

Miller, J.A., D.J. Teel, W.T. Peterson, and A.M. Baptista. 2014. Assessing the Relative Importance of Local and Regional Processes on the Survival of a Threatened Salmon Population. PLoS ONE. 9(6): e99814. doi:10.1371/journal.pone.0099814.

Moss, J.H., D.A. Beauchamp, A.D. Cross, K.W. Myers, E.V. Farley Jr, J.M. Murphy, and J.H. Helle. 2005. Evidence for Size-Selective Mortality after the First Summer of Ocean Growth by Pink Salmon. Trans. Am. Fish. Soc. 134: 1313-1322.

Passolt, G., and J. Anderson. 2013. A model linking ocean survival to smolt length, 2013. N. Pac. Anadr. Fish Comm. Tech. Rep. 9: 184-190. (Available at https://npafc.org)

R Core Team. 2016. R: A language and environment for statistical computing. R Foundation for Statistical Computing. Vienna, Austria.

Seitz, A.C., M.B. Courtney, M.D. Evans, and K. Manishin. 2019. Pop-up satellite archival tags reveal evidence of intense predation on large immature Chinook salmon (Oncorhynchus tshawytscha) in the North Pacific Ocean. Can. J. Fish. Aquat. Sci. 76: 1608-1615. doi:10.1139/cjfas-2018-0490.

Tucker, S., J.M. Hipfner, and M. Trudel. 2016. Size- and condition-dependent predation: a seabird disproportionately targets substandard individual juvenile salmon. Ecology. 97(2): 461-471. doi:10.1890/150564.1. 